\title{
Acidic Deposition and Climate Warming as Drivers of Tree Growth in High-Elevation Spruce-Fir Forests of the Northeastern US
}

\section{OPEN ACCESS}

Edited by:

Jesús Julio Camarero,

Spanish National Research Council (CS/C), Spain

Reviewed by:

Eryuan Liang,

Institute of Tibetan Plateau Research (CAS), China

Yann Vitasse,

Swiss Federal Institute for Forest,

Snow and Landscape Research

(WSL), Switzerland

*Correspondence:

Jay W. Wason

jay.wason@maine.edu

Specialty section:

This article was submitted to Temperate and Boreal Forests,

a section of the journal

Frontiers in Forests and Global

Change

Received: 19 August 2019 Accepted: 01 October 2019

Published: 17 October 2019

Citation:

Wason JW, Beier CM, Battles JJ and Dovciak M (2019) Acidic Deposition and Climate Warming as Drivers of

Tree Growth in High-Elevation

Spruce-Fir Forests of the Northeastern

US. Front. For. Glob. Change 2:63. doi: 10.3389/ffgc.2019.00063

\begin{abstract}
Jay W. Wason ${ }^{1,2 *}$, Colin M. Beier ${ }^{3}$, John J. Battles ${ }^{4}$ and Martin Dovciak ${ }^{2}$
${ }^{1}$ School of Forest Resources, University of Maine, Orono, ME, United States, ${ }^{2}$ Department of Environmental and Forest Biology, State University of New York College of Environmental Science and Forestry (SUNY ESF), Syracuse, NY, United States, ${ }^{3}$ Department of Forest and Natural Resources Management, State University of New York College of Environmental Science and Forestry (SUNY ESF), Syracuse, NY, United States, ${ }^{4}$ Department of Environmental Science, Policy and Management, University of California, Berkeley, Berkeley, CA, United States
\end{abstract}

Acid rain in eastern North America contributed to the widespread decline of red spruce in high-elevation spruce-fir forests. With recent reductions in acid deposition and a warming climate, resurgence of red spruce growth has been reported in some mountain areas. Based on an extensive tree-ring sampling network established across elevations (600 to $1,200 \mathrm{~m}$ above sea level) in spruce-fir forests on 10 mountains in the northeastern US (New York, Vermont, New Hampshire, and Maine), we investigated whether this resurgence was specific only to red spruce or if it occurred also in the co-dominant balsam fir. Furthermore, we tested if tree growth changes for both species were related to recent trends in acidic deposition and climate. Sharply increasing growth rates of red spruce were evident at all elevations and most closely correlated with increasing rainwater $\mathrm{pH}$. Although climate of the previous year (cool July and warm November) explained higher spruce growth in certain years, recent trends in climate did not drive observed increases in spruce growth. In contrast, balsam fir exhibited no regional growth surge during the period of spruce recovery. Thus, spruce growth resurgence appears to be mediated primarily by declining acid deposition and not climatic changes or stand dynamics that would also impact fir growth. Although high-elevation forests may ultimately be at risk for future warming-related heat and drought stress, the observed recent dramatic resurgence of spruce growth illustrates the benefits of policy-driven reductions in acidic deposition for the health and productivity of northeastern US forests.

\footnotetext{
Keywords: Abies balsamea, acidic deposition, balsam fir, Clean Air Act, climate warming, Picea rubens, red spruce, tree rings
}

\section{INTRODUCTION}

Acidic deposition has severely impacted major forested areas of Europe, Asia, and North America (Vet et al., 2014). Across the northeastern US, acidic deposition contributed to the widespread morbidity and mortality of high-elevation red spruce (Picea rubens) in the 1980's (Adams etal., 2012). This decline was specific to red spruce and compelling evidence revealed that acidic deposition leached membrane-bound calcium from foliage and decreased the freezing tolerance 
(Schaberg et al., 2000). Indeed, a characteristic symptom of spruce decline is the periodic occurrence of widespread foliar injury in winter (Kosiba et al., 2013; Wason et al., 2017b). However, despite several recent winter injury events, red spruce at high elevations in mountains throughout its range is now in a period of rapid growth (Wason et al., 2017b; Kosiba et al., 2018; Mathias and Thomas, 2018).

The recovery of red spruce has been attributed to trends in acidic deposition, climate change, and atmospheric $\mathrm{CO}_{2}$ concentrations (Wason et al., 2017b; Kosiba et al., 2018; Mathias and Thomas, 2018). Reduced emissions have led to a decrease in sulfate and nitrate deposition as well as a decrease in acidic deposition in the northeastern US that has been "rapid and relentless" after 1970 (Likens and Buso, 2012). Coincident with reductions in acidic deposition, annual temperatures have warmed $\sim 1.25^{\circ} \mathrm{C}$ since the $1960 \mathrm{~s}$ in the northeastern US (Hayhoe et al., 2007; Kunkel et al., 2013; Wason et al., 2017a) although this warming has been spatially and seasonally variable (Beier et al., 2012; Wason et al., 2017a). Red spruce responds positively to some aspects of climate warming (Gavin et al., 2008; Kosiba et al., 2018), however, many studies have found that red spruce growth and abundance responds negatively to increasing mean annual air temperatures (particularly above $11^{\circ} \mathrm{C}$ ) and increasing atmospheric pollution (Canham and Murphy, 2016, Appendix S1; Houle et al., 2012; Koo et al., 2014). Limited evidence also suggests that the recent increase in red spruce growth is related to $\mathrm{CO}_{2}$ fertilization (Mathias and Thomas, 2018), however $\mathrm{CO}_{2}$ fertilization does not always impact stem growth (Körner et al., 2005) and largescale studies have found no support for this effect in red spruce (Kosiba et al., 2018). Recent empirical studies generally support the negative impact of air pollution on tree growth but differences in research design, geographic scope, and analytical framework have led to contrasting conclusions about the relative contributions of how increasing air temperatures and decreasing acidic deposition contribute to enhanced red spruce growth (Kosiba et al., 2018; Mathias and Thomas, 2018).

Given the species-specific negative impacts of acidic deposition, recent studies have focused on red spruce. However, these montane conifer forests are co-dominated by red spruce and balsam fir (Abies balsamea) (Cogbill and White, 1991; Wason and Dovciak, 2017). Montane spruce-fir forests are considered sensitive high-elevation ecosystems susceptible to both air pollution (Friedland, 1989; McNulty et al., 2017) and climate change (Beckage et al., 2008; Wason et al., 2017a). However despite expectations of an "uphill retreat," montane spruce-fir range shifts have been species specific and delayed (Wason et al., 2017b) or downslope (Foster and D'Amato, 2015; Wason and Dovciak, 2017). Our inability to reliably predict near-term responses to abiotic drivers and the uncertainty related to the drivers of observed changes (Kosiba et al., 2018; Mathias and Thomas, 2018) suggest that we do not yet completely understand the contemporary environmental controls of spruce-fir forest growth. However, understanding the impacts of simultaneous global change stressors such as climate and atmospheric deposition on overall forest growth (not just on one species) is a priority for forest conservation and management under changing environmental conditions (Smith et al., 2009; Côté et al., 2016).

In this paper, we evaluate how long-term decreases in acidic deposition and increases in air temperature affected the dominant species in the spruce-fir forests across a broad region and across a range of elevations. We build upon an extensive network of research plots established in spruce-fir forests on mountains in four states in the northeastern US (Wason and Dovciak, 2017; Wason et al., 2017a,b). Our analysis incorporates the longest record of acidic deposition available in the northeastern US and provides a comprehensive examination of the drivers of tree growth across steep climatic gradients. To isolate the environmental effects on tree growth, we compared growth patterns in red spruce and balsam fir across elevational and latitudinal gradients. Balsam fir is considered less sensitive than red spruce to acidic deposition (DeHayes et al., 1999) and climate variability (Wason et al., 2017b) but represents a major component of the spruce-fir forest. Thus, balsam fir growth responses are important for understanding of the overall montane spruce-fir forest growth response in these high elevation systems. We expect that the decline in acidic deposition, rather than climate conditions, will be the major driver of increased red spruce growth. We also expect that balsam fir will show no concurrent growth resurgence.

\section{MATERIALS AND METHODS}

\section{Study Area}

In the northeastern US, spruce-fir forests typically occupy elevations over $\sim 750 \mathrm{~m}$ above sea level (a.s.l.) (Wason et al., 2017a). Spruce-fir forests are dominated by red spruce and balsam fir with lesser amounts of cordate birch (Betula papyrifera var. cordifolia). Balsam fir is the main canopy tree above $\sim 1,000 \mathrm{~m}$ a.s.l. and forms a treeline above $\sim 1,200 \mathrm{~m}$ a.s.l. (Wason and Dovciak, 2017).

\section{Field Methods and Tree-Core Processing}

On 10 mountains in the northeastern US, as part of a larger regional study of montane forests (Wason and Dovciak, 2017; Wason et al., 2017a,b), we established sampling sites at $100 \mathrm{~m}$ elevation intervals within the range of spruce-fir forest and its transition into hardwood forest at lower elevations (500 to 1,200 m a.s.l.; Figure 1; Wason and Dovciak, 2017; Wason et al., 2017a). In 2013, at each site we estimated stand-level basal area of overstory trees $(\mathrm{DBH}>10.14 \mathrm{~cm})$ using point-centered-quarter sampling (Morisita, 1960) at 15 points along a $225 \mathrm{~m}$ transect parallel to the elevation contour (Wason and Dovciak, 2017). We identified the highest, lowest, and a middle elevation site on each mountain for each species (red spruce and balsam fir) with at least five healthy canopy trees $(\mathrm{DBH}>20 \mathrm{~cm}$ ) available for coring (Table 1). Each tree was cored to the pith (two cores per tree taken from opposite sides) at breast height $(1.37 \mathrm{~m})$ parallel to the elevation contour. Cores were processed using standard dendrochronology procedures (Wason et al., 2017b). We mounted, sanded, and measured cores (raw ring widths) using a sliding scale micrometer (Velmex, Inc., Bloomfield, NY) and Acu-Rite encoder (Heidenhain 178 Corp., Shaumberg, IL). 


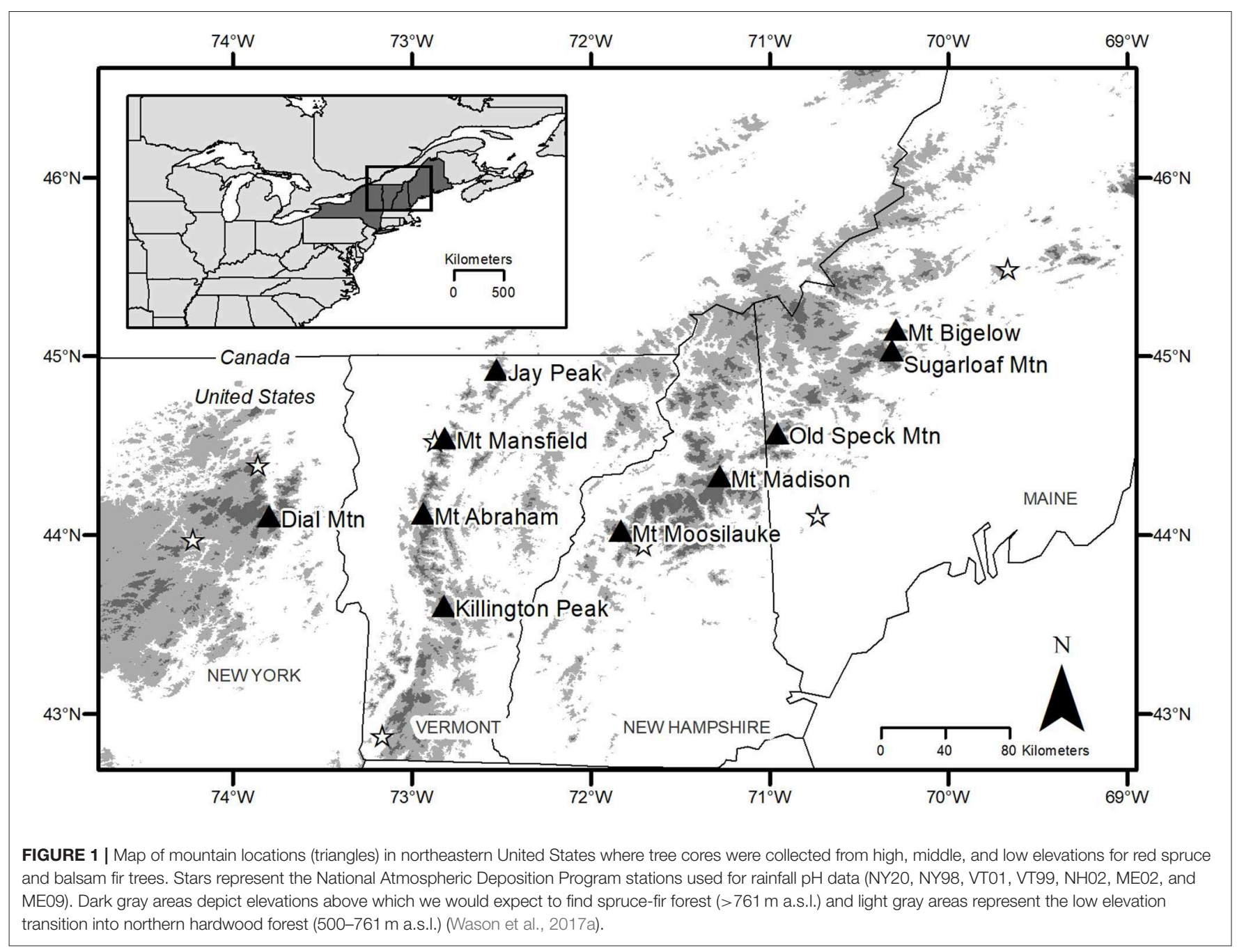

For cores that did not reach the tree pith, we used a template of concentric circles and the earliest 5 years of growth to estimate the age at breast height. Cores were crossdated using COFECHA (Holmes, 1983) and cores with a series intercorrelation below 0.4 were removed from the dataset ( $9 \%$ of spruce trees and $15 \%$ of balsam fir trees removed). Additionally, we limited each species dataset to only include years where (1) the mountain level Expressed Population Signal was $\geq 0.85$ (Wigley et al., 1984; Kosiba et al., 2013) and (2) data were available for that species at all sites. Final datasets spanned 1941-2012 for red spruce and 1965-2012 for balsam fir.

To verify that the elevational climate gradient was not confounded by tree age, size, and growth sensitivity across elevation, we used ANOVA and Tukey's Honest Significant Difference (HSD) to test for differences in mean age, DBH, and growth sensitivity (from COFECHA) across elevation groups (low, middle, and high; Table 1) for each species (blocking by mountain). We used ARSTAN (Cook, 1985) to derive a ring width index (RWI) as the residual chronology of a power-transformed (Cook and Peters, 1981) and detrended raw ring width series. Detrending was conducted with a Friedman
Variable Span Smoother (stiffness $=9$ ) to remove low frequency geometric and ecological noise (i.e., release events) in the raw ring width series (Friedman, 1984; Cook and Kairiukstis, 1990; Fritts, 2012). We calculated the yearly mean RWI and basal area increment (BAI) per tree and used the robust biweight mean to calculate the yearly average RWI and BAI per species at each site (Cook and Kairiukstis, 1990).

\section{Environmental Variables}

The mean daily maximum temperature for each month $\left(\mathrm{T}_{\max }\right)$, mean daily minimum temperature for each month $\left(\mathrm{T}_{\min }\right)$, and total precipitation in each month (precip) were derived for each mountain using the $4 \mathrm{~km}$ resolution gridded PRISM dataset for pixels within $8 \mathrm{~km}$ of each mountain summit (PRISM Climate Group, 2016). These variables were used to calculate the monthly Standardized PrecipitationEvapotranspiration Index (SPEI) with the Thornthwaite approximation of potential evapotranspiration in the R package "SPEI" (Beguería and Vicente-Serrano, 2017). To estimate precipitation chemistry time series for each mountain, we calculated inverse distance weighted mean annual rainfall $\mathrm{pH}$ 
TABLE 1 | Characteristics for red spruce (1941-2012) and balsam fir (1965-2012) trees grouped by elevation on mountains in northeastern United States.

\begin{tabular}{|c|c|c|c|c|c|c|c|c|c|c|}
\hline \multirow[b]{2}{*}{ Elev. } & \multicolumn{5}{|l|}{ Spruce } & \multicolumn{5}{|l|}{ Fir } \\
\hline & DBH (cm) & Age* (yrs) $^{*}$ & Sens. ${ }^{1},{ }^{\star *}$ & $\begin{array}{l}\text { \# trees } \\
\text { (sites }^{2} \text { ) }\end{array}$ & Elev. range & DBH (cm) & Age (yrs) & Sens. & \# trees $\left(\right.$ sites $\left.^{3}\right)$ & Elev. range \\
\hline High & $\begin{array}{c}30.3 \\
( \pm 1.2)^{A}\end{array}$ & $\begin{array}{c}155.3 \\
( \pm 12.0)^{A}\end{array}$ & $\begin{array}{c}0.23 \\
( \pm 0.007)^{A}\end{array}$ & $39(9)$ & $900-1,200$ & $\begin{array}{c}25.7 \\
( \pm 0.7)^{A}\end{array}$ & $\begin{array}{c}69.9 \\
( \pm 4.4)^{\mathrm{A}}\end{array}$ & $\begin{array}{c}0.18 \\
( \pm 0.005)^{A}\end{array}$ & $52(11)$ & $1,000-1,200$ \\
\hline Mid. & $\begin{array}{c}30.5 \\
( \pm 1.5)^{\mathrm{A}}\end{array}$ & $\begin{array}{c}112.1 \\
( \pm 8.7)^{\mathrm{B}}\end{array}$ & $\begin{array}{c}0.21 \\
( \pm 0.007)^{B}\end{array}$ & $41(9)$ & $800-1,000$ & $\begin{array}{c}26.6 \\
( \pm 0.9)^{A}\end{array}$ & $\begin{array}{c}75.4 \\
( \pm 4.7)^{\mathrm{A}}\end{array}$ & $\begin{array}{c}0.18 \\
( \pm 0.006)^{A}\end{array}$ & $46(10)$ & $800-1,100$ \\
\hline Low & $\begin{array}{c}31.2 \\
( \pm 1.3)^{A}\end{array}$ & $\begin{array}{c}115.1 \\
( \pm 14.3)^{B}\end{array}$ & $\begin{array}{c}0.21 \\
( \pm 0.009)^{A B}\end{array}$ & $39(9)$ & $600-900$ & $\begin{array}{c}26.1 \\
( \pm 1.2)^{A}\end{array}$ & $\begin{array}{c}79.8 \\
( \pm 3.3)^{\mathrm{A}}\end{array}$ & $\begin{array}{c}0.19 \\
(0.007)^{A}\end{array}$ & 34 (10) & $700-900$ \\
\hline
\end{tabular}

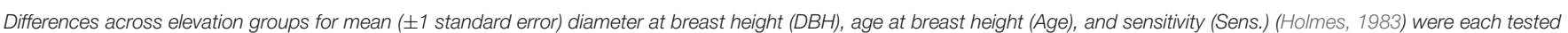

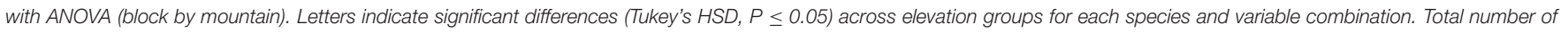
trees (and sites) and elevation range ( $m$ a.s.I.) reported for each species and elevation group. Two cores were collected per tree.

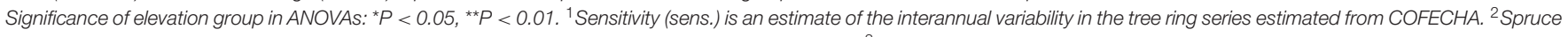

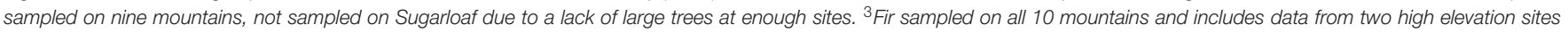
on Sugarloaf.

from monthly bulk precipitation $\mathrm{pH}$ data collected at seven National Atmospheric Deposition Program sites across the region (NY20, NY98, VT01, VT99, NH02, ME02, and ME09). Data for these sites was available for 1980-2012 and was extended an additional 15 years beyond previous studies by including data from the Hubbard Brook Experimental Forest, NH (Watershed 6; 1965-2012; Figure 1, Figure S4). The effect of elevation on environmental variables was accounted for by including elevation and potential interactions between elevation and environmental variables in all analyses. Forest competition may impact tree growth and was accounted for by using stand level basal area of overstory trees $(>10.14 \mathrm{~cm} \mathrm{DBH})$ (Wason and Dovciak, 2017; Wason et al., 2017b).

\section{Modeling Tree-Growth as a Function of Climate and Acidic Deposition}

We modeled BAI as a function of climate and rainfall $\mathrm{pH}$ by first selecting the climate variables most related to tree growth. We relied on response function analysis to identify relevant climate variables. Response function analysis reduces the effects of the multicollinearity inherent in climate data (Briffa and Cook, 1990; Biondi and Waikul, 2004; Fritts, 2012). Therefore, we used this approach to calculate correlation coefficients between climate variables and site-level RWI. To select climate variables for BAI models, we calculated the mean correlation coefficients (from response functions) for each climate variable by species and elevation group and assessed significance with bootstrapped $99.9 \%$ confidence intervals (10,000 bootstraps). Climate variables were included in the BAI models as main effects if the variable was significant in all elevation groups from the response function analysis (Figures S2, S3). If the climate variable was significant in at least one elevation group, we used linear-mixed-models to test whether there was a significant effect of elevation on that correlation coefficient (with a random intercept for mountain). If there was a significant effect of elevation, that climate variable was included in the full BAI models as an interaction with elevation. The full BAI models for each species, therefore, included fixed effects for tree age, tree radius, competition (stand basal area), climate variables (some interacting with elevation), and rainfall
$\mathrm{pH}$ (interacting with elevation). BAI models included a random effect for site nested within mountain and a first order serial autocorrelation term.

Prior to model fitting, BAI was log transformed (to satisfy normality) and all predictor variables were scaled to facilitate comparison $($ mean $=0$, standard deviation $=1$ ). Full BAI models were reduced by first removing variables with variance inflation factors above 10 (Neter et al., 1989). Next, we used backwards AIC selection of elevation, $\mathrm{pH}$, and climate variables to determine the final model for each species. Tree age, tree radius, and competition were retained in all models to account for their known impact on growth. Using the final model for each species, the variance explained by fixed effects (marginal $R^{2}$ ) and by fixed and random effects (conditional $R^{2}$ ) was calculated following Nakagawa and Schielzeth (2013). Finally, for each species we summarized the effects of $\mathrm{pH}$, temperature, and moisture on BAI by comparing predicted BAI at each site with predicted BAI when the long-term trend in each variable was removed (i.e., variables held at their means). Unless noted otherwise, all analyses were conducted in R (R Core Team, 2015) with the dplR (Bunn et al., 2015), nlme (Pinheiro et al., 2016), bootRes (Zang, 2012), and boot (Canty and Ripley, 2016) packages.

\section{RESULTS}

Red spruce growth (BAI) exhibited an increasing trend since the mid-1990s and reached the greatest values between 2009 and 2012 across all elevations (Figure 2A). Red spruce growth patterns were consistent among all sites (Figure 2A, Figures S1A, C) suggesting common driver(s) of growth resurgence across the region.

Balsam fir growth (BAI) did not exhibit this large growth increase, but had gradually increasing BAI at low elevations and relatively stable BAI at middle and high elevations since the mid1980s (Figure 2B). Models of red spruce (Figure 2C) and balsam fir (Figure 2D) BAI captured 51\% and 39\% of the variability in BAI for each species, respectively (Table 2 ).

The overall $62 \%$ average increase in red spruce BAI since the 1960 s was primarily related to concomitant increases 


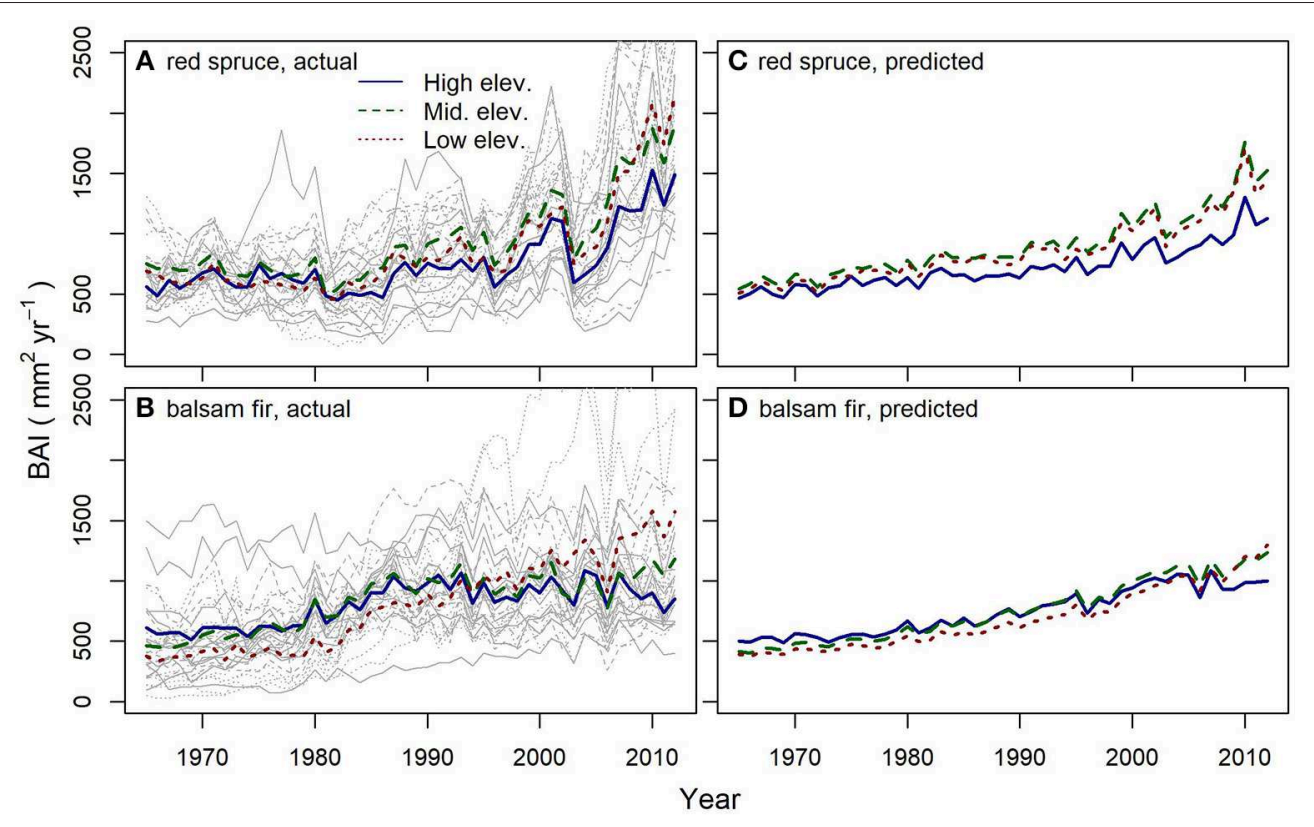

FIGURE 2 | Recent trends in basal area increment (BAl, $\mathrm{mm}^{2} \mathrm{yr}^{-1}$ ) for red spruce (A) and balsam fir (B) in high, middle, and low elevation groups (depicted by solid blue, dashed green, and dotted red lines, respectively) on 10 mountains in the northeastern US. Predicted BAI for red spruce (C) and balsam fir (D) from the best linear mixed effects models including the effects of tree age, tree size, competition, elevation, regional climate, and rainfall pH (model results and significance of the individual predictors in Table 2). Gray lines in (A,B) represent mean site BAl for each species. Note that 95\% confidence intervals (not shown for clarity) indicated that there were no mean differences in BAl among the elevation groups for any year.

in rainfall $\mathrm{pH}$, i.e., a strong declining trend in bulk acidic deposition (Figure 3A; Table 2; Figure S4A). Climate also influenced red spruce growth, but the magnitude of the response was less compared to $\mathrm{pH}$ (Figures 3A,C,E, Table 2). Out of all temperature variables, spruce growth responded most positively to past warm fall temperatures (cf. $\mathrm{T}_{\text {min }}$ previous November) and most negatively to past summer heat (cf. $\mathrm{T}_{\max }$ previous July) (Table 2). Interestingly, the combined effects of multiple temperature variables on growth was associated with some recent years of high growth (Figure 3C). For example, in 2000, 2001, and 2009 the cool maximum temperatures in July and warm minimum temperatures in November (Figure S4B) corresponded to high red spruce BAI in the subsequent year (Figures 2A, 3C). However, when compared to acidic deposition, climate warming did not contribute to the observed longer-term trend in BAI (Figures 2A, 3A). Red spruce also experienced slight increases in growth related to spring moisture availability (March SPEI; Table 2) but net changes in moisture did not influence long-term growth (Figure 3E, Figure S4D).

In general, balsam fir growth was less sensitive to rainfall $\mathrm{pH}$ and climate. Balsam fir growth declined with increasing rainfall $\mathrm{pH}$ but only at higher elevations (Figure 3B; Table 2). This growth decline was observed particularly in dense high elevation stands recently reaching basal areas $>50 \mathrm{~m}^{2}$ $\mathrm{ha}^{-1}$. Climate had weak effects on fir growth (Figures 3D,F, Figures S1B,D). There were slight and divergent growth responses to air temperature (Table 2) and a small decrease in growth with increasing precipitation (Table 2). However, the net effect of temperature (Figure 3D) and moisture (Figure 3F) changes did not correlate with a long-term change in balsam fir growth.

\section{DISCUSSION}

Our results indicate that climate warming is unlikely to be the primary reason for the regional surge in montane red spruce growth for several reasons. First, the temperature variables that were most strongly related to red spruce growth (Table 2) have warmed very little or not at all since the 1960s (Figure S4; Wason et al., 2017a). Second, recent climate conditions resulted in some years with high growth in the last $\sim 20$ years but not a long-term increase (Figure 3C). And third, if climate were driving recent growth trends, we would expect differential responses to climate variables along the broad elevational and latitudinal gradients studied (Koo et al., 2014; Juday et al., 2015; Wason et al., 2017a). For example, we did not see stronger growth responses to warming at higher elevations or latitudes where trees should be more limited by temperature (Juday et al., 2015; Sherriff et al., 2017). Warming may have led to fewer opportunities for winter injury (Friedland et al., 1984; Hamburg and Cogbill, 1988; DeHayes et al., 1999) that interacted with reduced acidic deposition to drive the red spruce growth resurgence. However, the drivers of winter injury susceptibility are not straightforward (Schaberg et al., 2011). For example, the intense warming in January and February (Wason et al., 2017a) may increase the likelihood of midwinter 
TABLE 2 | Summary of best linear mixed effects models predicting changes in basal area increment (BAl; $\mathrm{mm}^{2} \mathrm{yr}^{-1}$ ) of red spruce and balsam fir between 1965 and 2012.

\begin{tabular}{|c|c|c|c|c|c|c|c|c|}
\hline Species & $R^{2}$ mar. & $R^{2}$ cond. & Coefficient ${ }^{\star}$ & Value & SE & d.f. & $t$-value & $P$-value \\
\hline \multirow[t]{9}{*}{ Spruce } & 0.36 & 0.51 & (Intercept) & 6.655 & 0.059 & 1,257 & 112.8 & $<0.001$ \\
\hline & & & Tree Age & -0.196 & 0.076 & 1,257 & -2.6 & 0.010 \\
\hline & & & Competition & 0.104 & 0.055 & 16 & 1.9 & 0.076 \\
\hline & & & $\mathrm{pH}$ & 0.117 & 0.020 & 1,257 & 5.7 & $<0.001$ \\
\hline & & & $T_{\max }$ prev July & -0.054 & 0.006 & 1,257 & -8.4 & $<0.001$ \\
\hline & & & $T_{\max }$ prev Sept & -0.015 & 0.007 & 1,257 & -2.2 & 0.031 \\
\hline & & & $\mathrm{T}_{\min }$ April & 0.006 & 0.006 & 1,257 & 0.9 & 0.348 \\
\hline & & & $\mathrm{T}_{\min }$ prev June & 0.037 & 0.007 & 1,257 & 5.5 & $<0.001$ \\
\hline & & & $\mathrm{T}_{\min }$ prev Nov & 0.072 & 0.005 & 1,257 & 13.8 & $<0.001$ \\
\hline \multirow[t]{11}{*}{ Fir } & 0.39 & 0.39 & (Intercept) & 6.504 & 0.058 & 1,445 & 112.5 & $<0.001$ \\
\hline & & & Tree Age & 0.028 & 0.084 & 1,445 & 0.3 & 0.734 \\
\hline & & & Tree Radius & 0.412 & 0.079 & 1,445 & 5.2 & $<0.001$ \\
\hline & & & Competition & 0.036 & 0.060 & 19 & 0.6 & 0.553 \\
\hline & & & $\mathrm{pH}$ & -0.050 & 0.018 & 1,445 & -2.7 & 0.007 \\
\hline & & & Elevation & 0.016 & 0.061 & 19 & 0.3 & 0.788 \\
\hline & & & $T_{\max }$ Sept & 0.028 & 0.006 & 1,445 & 4.6 & $<0.001$ \\
\hline & & & $\mathrm{T}_{\max }$ prev Oct & -0.012 & 0.005 & 1,445 & -2.5 & 0.012 \\
\hline & & & $\mathrm{T}_{\max }$ prev Nov & 0.028 & 0.004 & 1,445 & 6.2 & $<0.001$ \\
\hline & & & Precip Jan & -0.018 & 0.005 & 1,445 & -3.5 & 0.001 \\
\hline & & & Precip Feb & -0.009 & 0.005 & 1,445 & -1.9 & 0.063 \\
\hline
\end{tabular}

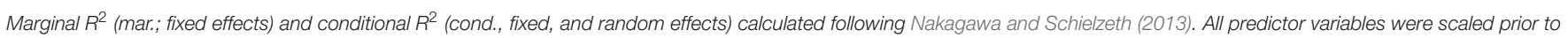
model fitting (mean $=0$, standard deviation $=1$ ).

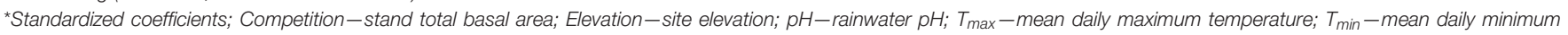
temperature; SPEI-Standardized Precipitation-Evaporation Index; precip-monthly total precipitation; prev-previous year.

thaws that can increase, rather than decrease, chances of injury (Schaberg et al., 2011).

Our analysis suggests that reductions in acidic deposition since 1990 (Figure S4A) have been the primary driver of steep increases in red spruce growth across the northeastern US. The positive relationship between increasing rainwater $\mathrm{pH}$ and spruce growth is consistent throughout the region and across the elevation gradient. The rapid increase in spruce growth following reductions in acidic deposition is similar to the rapid recovery of Abies alba in Europe although the physiological mechanisms of that decline are still uncertain (Elling et al., 2009). Although the right combination of climatic conditions can promote highgrowth years for red spruce (such as 2001, 2002, and 2010), these climatic factors have not changed consistently over this period in a way that would drive a strong and persistent trend of improving growth (Wason et al., 2017a). The asynchrony between growth trends of red spruce and balsam fir further suggests that other potential drivers of tree growth that should influence both species in a similar way are not the primary cause of the recent growth trends in red spruce. For example, $\mathrm{CO}_{2}$ fertilization has been suggested as a driver of the recent red spruce growth increase (Mathias and Thomas, 2018), however (i) other studies contradict this finding (Kosiba et al., 2018), (ii) lowland stands that received far less acid rain show no recent spruce growth increase (Teets et al., 2018), and (iii) we see no evidence of increased growth in co-dominant balsam fir suggesting that $\mathrm{CO}_{2}$ fertilization has a limited effect in these forests.

Balsam fir, has not experienced a region-wide increase in growth. The slight decline in growth for some high elevation balsam fir trees was correlated with increasing rainfall $\mathrm{pH}$ but was mostly sites with exceptionally high stand basal areas and may also be driven by high competition with rapidly growing spruce that was not captured by our models. The increase in basal area growth of balsam fir at some low elevation sites is consistent 


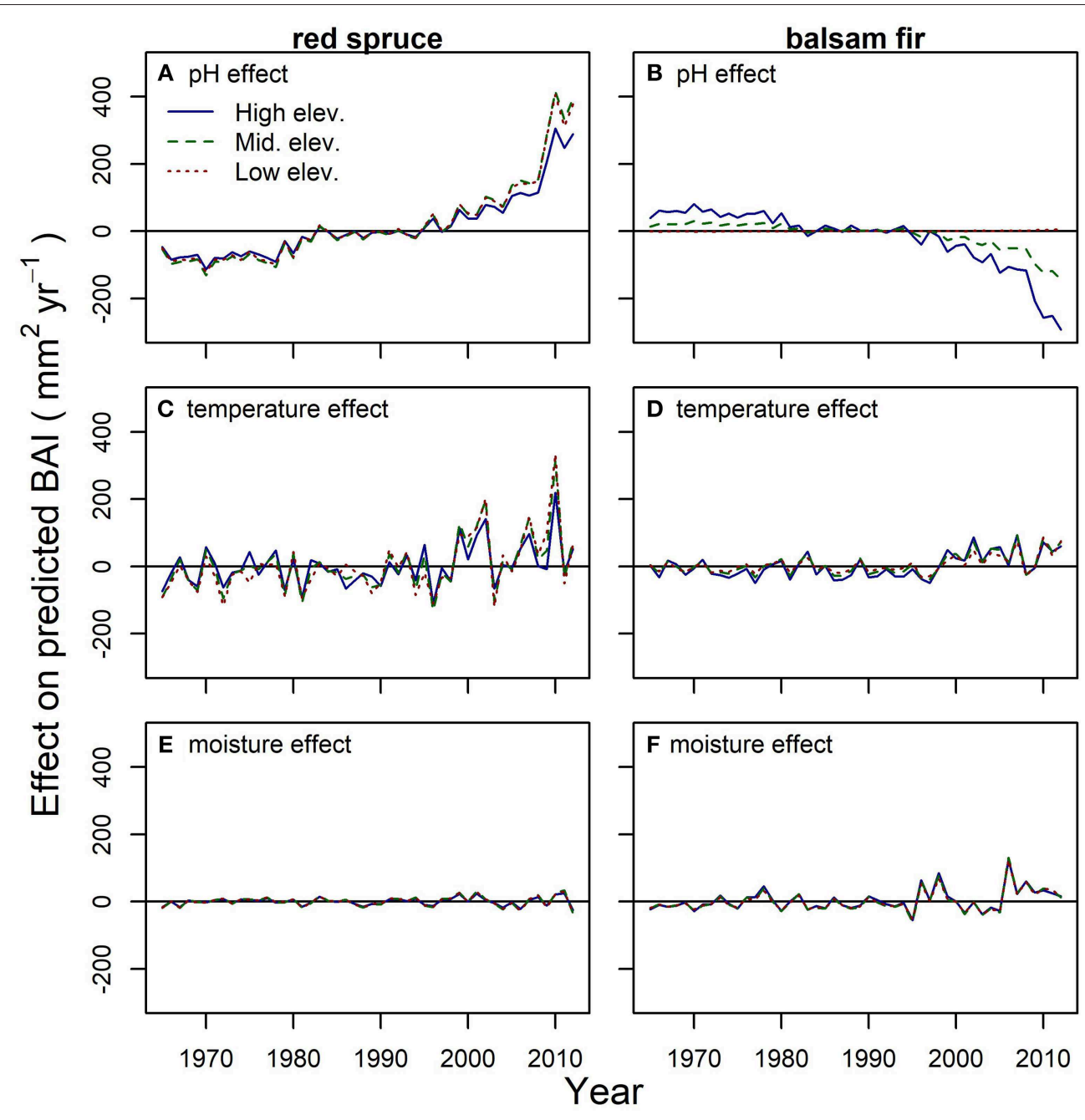

FIGURE 3 | The separate effects of acidic deposition (A,B), temperature (C,D), and moisture (E,F) on growth from models of basal area increment (BAI) for red spruce (A,C,E) and balsam fir (B,D,F) in the northeastern US (1965-2012). Plots represent the impact that pH, temperature, or moisture had on predicted tree-growth (see Figures 2C,D) averaged within high, middle, and low elevation groups. The impact of each variable was calculated as the difference between predicted BAl from the full model (Figures $\mathbf{2} \mathbf{C , D}$ ) and a model where the variable is held constant at its mean (i.e., no change in that variable over time). Positive values indicate the variable resulted in higher predicted growth in that year. BAI was predicted from the best linear mixed effects models including the effects of tree age, tree size, competition, elevation, regional climate, and rainfall pH (Table 2). Statistical tests of these effects are in Table 2.

with reports from one other mountain (Wason et al., 2017b) but was not consistent across all mountains in this study suggesting this effect may be limited to stand level dynamics on a few low elevation sites.

Our results, when considered in light of the known physiological impacts of acidic deposition on red spruce (DeHayes et al., 1999; Schaberg et al., 2000) and in conjunction with insights from previous studies (Wason et al., 2017b; Kosiba et al., 2018; Mathias and Thomas, 2018) provide compelling evidence of the efficacy of policies to reduce atmospheric pollution and its negative impacts on ecosystem services and human health (Beier et al., 2017; Sullivan et al., 2018). The resurgence of red spruce, a foundational species in high elevation forests of northeastern North America, fulfills the original purpose of the law "to reduce the adverse effects of acid deposition through reductions in annual emissions" (Clean Air
Act, 1990). Climate change accounted for only a small amount of the long-term growth trends in red spruce and balsam fir in our study. However, as rainfall $\mathrm{pH}$ stabilizes near pre-industrial levels, future climate warming will continue to affect these forests at increasing levels (Wason et al., 2017a). For example, continued warming minimum temperatures in November may potentially benefit growth of red spruce but this positive effect may be outweighed over time by the negative impacts of extreme heat in July (Table 2) and potential early season droughts in March. We stress that while the growth of high elevation red spruce has greatly increased, red spruce dominance in eastern forests is still well below historical levels (Hamburg and Cogbill, 1988; Wason et al., 2017b) and other tree species sensitive to atmospheric deposition-related soil acidification (e.g., sugar maple) are still experiencing declines (Bishop et al., 2015). While reduced atmospheric deposition has directly benefited red spruce 
growth, acid deposition will have a lasting legacy in northeastern U.S. forest ecosystems as acidified soils and plant communities are slow to recover (Driscoll et al., 2001; Battles et al., 2014; Lawrence et al., 2015; Zarfos et al., 2019); importantly, acidic deposition still remains a significant form of pollution in many forested areas globally (Vet et al., 2014).

\section{DATA AVAILABILITY STATEMENT}

The datasets generated for this study are available for download from The DendroEcological Network at https://doi.org/10. 18125/sg4ksc.

\section{AUTHOR CONTRIBUTIONS}

JW, CB, JB, and MD designed the study and wrote the manuscript. JW collected and analyzed the data.

\section{FUNDING}

This research was supported by the US Forest Service Northeastern States Research Cooperative, Edna Bailey Sussman Foundation, and partly by the National Science Foundation (BCS-GSS-1759724) and the USDA National Institute of Food

\section{REFERENCES}

Adams, M. B., Cogbill, C., Cook, E. R., DeHayes, D. H., Fernandez, I. J., Jensen, K. F., et al. (2012). Ecology and Decline of Red Spruce in the Eastern United States. New York, NY: Springer-Verlag.

Battles, J. J., Fahey, T. J., Driscoll, C. T., Blum, J. D., and Johnson, C. E. (2014). Restoring soil calcium reverses forest decline. Environ. Sci. Technol. Lett. 1, 15-19. doi: 10.1021/ez400033d

Beckage, B., Osborne, B., Gavin, D. G., Pucko, C., Siccama, T., and Perkins, T. (2008). A rapid upward shift of a forest ecotone during 40 years of warming in the Green Mountains of Vermont. Proc. Natl. Acad. Sci. U.S.A. 105, 4197-4202. doi: 10.1073/pnas.0708921105

Beguería, S., and Vicente-Serrano, S. M. (2017). SPEI: Calculation of the Standardised Precipitation-Evapotranspiration Index. Available online at: https://CRAN.R-project.org/package=SPEI (accessed May 14, 2018).

Beier, C. M., Caputo, J., Lawrence, G. B., and Sullivan, T. J. (2017). Loss of ecosystem services due to chronic pollution of forests and surface waters in the Adirondack region (USA). J. Environ. Manage. 191, 19-27. doi: 10.1016/j.jenvman.2016.12.069

Beier, C. M., Signell, S. A., Luttman, A., and DeGaetano, A. T. (2012). Highresolution climate change mapping with gridded historical climate products. Landsc. Ecol. 27, 327-342. doi: 10.1007/s10980-011-9698-8

Biondi, F., and Waikul, K. (2004). DENDROCLIM2002: A C++ program for statistical calibration of climate signals in tree-ring chronologies. Comput. Geosci. 30, 303-311. doi: 10.1016/j.cageo.2003.11.004

Bishop, D. A., Beier, C. M., Pederson, N., Lawrence, G. B., Stella, J. C., and Sullivan, T. J. (2015). Regional growth decline of sugar maple (Acer saccharum) and its potential causes. Ecosphere 6:art179. doi: 10.1890/ES1500260.1

Briffa, K. R., and Cook, E. R. (1990). Methods of Response Function Analysis. Dordrecht: Kluwer.

Bunn, A., Korpela, M., Biondi, F., Campelo, F., Mérian, P., Qeadan, F., et al. (2015). dplR: Dendrochronology Program Library in R. Available online at: https://cran. r-project.org/web/packages/dplR/index.html (accessed February 26, 2016).

Côté, I. M., Darling, E. S., and Brown, C. J. (2016). Interactions among ecosystem stressors and their importance in conservation. Proc. R. Soc. B Biol. Sci. 283:20152592. doi: 10.1098/rspb. 2015.2592 and Agriculture, McIntire Stennis Program (Project Number ME0-42001, Maine Agricultural and Forest Experiment Station Publication Number 3672).

\section{ACKNOWLEDGMENTS}

We thank Adam Busman, Dan Bishop, John Sanders, and Andrew Gotham for help collecting and processing tree cores. Ali Kosiba shared data from high elevations on Mount Mansfield. Hubbard Brook provided rainfall pH data. Research permits were provided by the New York State Department of Environmental Conservation; Vermont Department of Forests, Parks, and Recreation; New Hampshire Department of Resources and Economic Development; Maine Department of Agriculture, Conservation, and Forestry; and the Green and White Mountain National Forests. Site access and logistical support was provided by Sugarloaf Ski Resort, Dartmouth College, Vermont Monitoring Cooperative, and Ausable Club.

\section{SUPPLEMENTARY MATERIAL}

The Supplementary Material for this article can be found online at: https://www.frontiersin.org/articles/10.3389/ffgc.2019. 00063/full\#supplementary-material

Canham, C. D., and Murphy, L. (2016). The demography of tree species response to climate: sapling and canopy tree growth. Ecosphere 7:e01474. doi: $10.1002 /$ ecs 2.1474

Canty, A., and Ripley, B. (2016). boot: Bootstrap Functions. Available online at: https://cran.r-project.org/web/packages/boot/index.html (accessed February 26, 2016).

Clean Air Act (1990). “Amendments to the Clean Air Act of 1990," in Title IV; Section 401. (b). Clean Air Act.

Cogbill, C. V., and White, P. S. (1991). The latitude-elevation relationship for spruce-fir forest and treeline along the Appalachian mountain chain. Vegetation 94, 153-175. doi: 10.1007/BF00032629

Cook, E. R. (1985). A Time Series Analysis Approach to Tree Ring Standardization (thesis). University of Arizona, Tucson, AZ, United States. Available online at: https://trr.arizona.edu/content/time-series-analysis-approach-treering-standardization

Cook, E. R., and Kairiukstis, L. A. (1990). Methods of Dendrochronology: Applications in the Environmental Sciences. Dordrecht: Springer Science+Business Media.

Cook, E. R., and Peters, K. (1981). The smoothing spline: a new approach to standardizing forest interior tree-ring width series for dendroclimatic studies. Tree-Ring Bull. 41, 45-54.

DeHayes, D. H., Schaberg, P. G., Hawley, G. J., and Strimbeck, G. R. (1999). Acid rain impacts on calcium nutrition and forest health. BioScience 49, 789-800. doi: $10.2307 / 1313570$

Driscoll, C. T., Lawrence, G. B., Bulger, A. J., Butler, T. J., Cronan, C. S., Eagar, C., et al. (2001). Acidic deposition in the northeastern United States: sources and inputs, ecosystem effects, and management strategies. BioScience 51, 180-198. doi: 10.1641/0006-3568(2001)051[0180:ADITNU]2.0.CO;2

Elling, W., Dittmar, C., Pfaffelmoser, K., and Rötzer, T. (2009). Dendroecological assessment of the complex causes of decline and recovery of the growth of silver fir (Abies alba Mill.) in Southern Germany. For. Ecol. Manag. 257, 1175-1187. doi: 10.1016/j.foreco.2008.10.014

Foster, J. R., and D'Amato, A. W. (2015). Montane forest ecotones moved downslope in northeastern US in spite of warming between 1984 and 2011. Glob. Change Biol. 21, 4497-4507. doi: 10.1111/gcb.13046

Friedland, A. J. (1989). Recent changes in the montane spruce-fir forests of the northeastern United States. Environ. Monit. Assess. 12, 237-244. doi: 10.1007/BF00394803 
Friedland, A. J., Gregory, R. A., Karenlampi, L., and Johnson, A. H. (1984). Winter damage to foliage as a factor in red spruce decline. Can. J. For. Res. 14, 963-965. doi: $10.1139 / \mathrm{x} 84-173$

Friedman, J. H. (1984). A Variable Span Smoother. DTIC Document. Available online at: http://oai.dtic.mil/oai/oai?verb=getRecordandmetadataPrefix = htmlandidentifier=ADA148241 (accessed December 15, 2015).

Fritts, H. C. (2012). Tree Rings and Climate. New York, NY: Academic Press Inc.

Gavin, D. G., Beckage, B., and Osborne, B. (2008). Forest dynamics and the growth decline of red spruce and sugar maple on Bolton Mountain, Vermont: a comparison of modeling methods. Can. J. For. Res. 38, 2635-2649. doi: 10.1139/X08-106

Hamburg, S. P., and Cogbill, C. V. (1988). Historical decline of red spruce populations and climatic warming. Nature 331, 428-431. doi: $10.1038 / 331428 \mathrm{a} 0$

Hayhoe, K., Wake, C. P., Huntington, T. G., Luo, L., Schwartz, M. D., Sheffield, J., et al. (2007). Past and future changes in climate and hydrological indicators in the US Northeast. Clim. Dyn. 28, 381-407. doi: 10.1007/s00382-006-0187-8

Holmes, R. L. (1983). Computer-assisted quality control in tree-ring dating and measurement. Tree-Ring Bull. 43, 69-78.

Houle, D., Richard, P. J., Ndzangou, S. O., and Richer-Laflèche, M. (2012). Compositional vegetation changes and increased red spruce abundance during the Little Ice Age in a sugar maple forest of north-eastern North America. Plant Ecol. 213, 1027-1035. doi: 10.1007/s11258-012-0062-0

Juday, G. P., Alix, C., and Grant, I. I. I., T. A. (2015). Spatial coherence and change of opposite white spruce temperature sensitivities on floodplains in Alaska confirms early-stage boreal biome shift. For. Ecol. Manag. 350, 46-61. doi: 10.1016/j.foreco.2015.04.016

Koo, K. A., Patten, B. C., Teskey, R. O., and Creed, I. F. (2014). Climate change effects on red spruce decline mitigated by reduction in air pollution within its shrinking habitat range. Ecol. Model. 293, 81-90. doi: 10.1016/j.ecolmodel.2014.07.017

Körner, C., Asshoff, R., Bignucolo, O., Hättenschwiler, S., Keel, S. G., PeláezRiedl, S., et al. (2005). Carbon flux and growth in mature deciduous forest trees exposed to elevated $\mathrm{CO}_{2}$. Science 309, 1360-1362. doi: 10.1126/science.11 13977

Kosiba, A. M., Schaberg, P. G., Hawley, G. J., and Hansen, C. F. (2013). Quantifying the legacy of foliar winter injury on woody aboveground carbon sequestration of red spruce trees. For. Ecol. Manag. 302, 363-371. doi: $10.1016 /$ j.foreco.2013.03.006

Kosiba, A. M., Schaberg, P. G., Rayback, S. A., and Hawley, G. J. (2018). The surprising recovery of red spruce growth shows links to decreased acid deposition and elevated temperature. Sci. Total Environ. 637-638, 1480-1491. doi: 10.1016/j.scitotenv.2018.05.010

Kunkel, K., Stevens, L., Stevens, S., Sun, L., Janssen, E., Wuebbles, D., et al. (2013). Part 1. Climate of the Northeast U.S. Washington, DC: National Oceanic and Atmospheric Administration.

Lawrence, G. B., Hazlett, P. W., Fernandez, I. J., Ouimet, R., Bailey, S. W., Shortle, W. C., et al. (2015). Declining acidic deposition begins reversal of forest-soil acidification in the northeastern US and eastern Canada. Environ. Sci. Technol. 49, 13103-13111. doi: 10.1021/acs.est.5b02904

Likens, G. E., and Buso, D. C. (2012). Dilution and the elusive baseline. Environ. Sci. Technol. 46, 4382-4387. doi: 10.1021/es3000189

Mathias, J. M., and Thomas, R. B. (2018). Disentangling the effects of acidic air pollution, atmospheric $\mathrm{CO}_{2}$, and climate change on recent growth of red spruce trees in the Central Appalachian Mountains. Glob. Change Biol. 24, 3938-3953. doi: $10.1111 /$ gcb. 14273

McNulty, S. G., Boggs, J. L., Aber, J. D., and Rustad, L. E. (2017). Sprucefir forest changes during a 30-year nitrogen saturation experiment. Sci. Total Environ. 605-606, 376-390. doi: 10.1016/j.scitotenv.2017. 06.147

Morisita, M. (1960). A New Method for the Estimation of Density by the Spacing Method Applicable to Non-Randomly Distributed Populations. US Department of Agriculture, Forest Service, Division of Range and Wildlife Habitat Research.

Nakagawa, S., and Schielzeth, H. (2013). A general and simple method for obtaining R2 from generalized linear mixed-effects models. Methods Ecol. Evol. 4, 133-142. doi: 10.1111/j.2041-210x.2012.00261.x

Neter, J., Wasserman, W., and Kutner, M. H. (1989). Applied Linear Regression Models. New York, NY: Richard D. Irwin.
Pinheiro, J., Bates, D., DebRoy, S., Sarkar, D., and R Core Team (2016). nlme: Linear and Nonlinear Mixed Effects Models. Available online at: https://cran. r-project.org/web/packages/nlme/index.html (accessed February, 26, 2016).

PRISM Climate Group, Oregon State University (2016). Northwest Alliance for Computational Science and Engineering. Available online at: http://www.prism. oregonstate.edu

R Core Team (2015). R: A Language and Environment for Statistical Computing. Vienna, Austria: R Foundation for Statistical Computing. Available online at: http://www.R-project.org/

Schaberg, P. G., DeHayes, D. H., Hawley, G. J., Strimbeck, G. R., Cumming, J. R., Murakami, P. F., et al. (2000). Acid mist and soil Ca and Al alter the mineral nutrition and physiology of red spruce. Tree Physiol. 20, 73-85. doi: 10.1093/treephys/20.2.73

Schaberg, P. G., Lazarus, B. E., Hawley, G. J., Halman, J. M., Borer, C. H., and Hansen, C. F. (2011). Assessment of weather-associated causes of red spruce winter injury and consequences to aboveground carbon sequestration. Can. J. For. Res. 41, 359-369. doi: 10.1139/X10-202

Sherriff, R. L., Miller, A. E., Muth, K., Schriver, M., and Batzel, R. (2017). Spruce growth responses to warming vary by ecoregion and ecosystem type near the forest-tundra boundary in south-west Alaska. J. Biogeogr. 44, 1457-1468. doi: $10.1111 /$ jbi. 12968

Smith, M. D., Knapp, A. K., and Collins, S. L. (2009). A framework for assessing ecosystem dynamics in response to chronic resource alterations induced by global change. Ecology 90, 3279-3289. doi: 10.1890/08-1815.1

Sullivan, T. J., Driscoll, C. T., Beier, C. M., Burtraw, D., Fernandez, I. J., Galloway, J. N., et al. (2018). Air pollution success stories in the United States: the value of long-term observations. Environ. Sci. Policy 84, 69-73. doi: 10.1016/j.envsci.2018.02.016

Teets, A., Fraver, S., Weiskittel, A. R., and Hollinger, D. Y. (2018). Quantifying climate-growth relationships at the stand level in a mature mixed-species conifer forest. Glob. Change Biol. 24, 3587-3602. doi: 10.1111/gcb.14120

Vet, R., Artz, R. S., Carou, S., Shaw, M., Ro, C.-U., Aas, W., et al. (2014). A global assessment of precipitation chemistry and deposition of sulfur, nitrogen, sea salt, base cations, organic acids, acidity and $\mathrm{pH}$, and phosphorus. Atmos. Environ. 93, 3-100. doi: 10.1016/j.atmosenv.2013.10.060

Wason, J. W., Bevilacqua, E., and Dovciak, M. (2017a). Climates on the move: Implications of climate warming for species distributions in mountains of the northeastern United States. Agric. For. Meteorol. 246, 272-280. doi: 10.1016/j.agrformet.2017.05.019

Wason, J. W., and Dovciak, M. (2017). Tree demography suggests multiple directions and drivers for species range shifts in mountains of Northeastern United States. Glob. Change Biol. 23, 3335-3347. doi: 10.1111/gcb.13584

Wason, J. W., Dovciak, M., Beier, C. M., and Battles, J. J. (2017b). Tree growth is more sensitive than species distributions to recent changes in climate and acidic deposition in the northeastern United States. J. Appl. Ecol. 54, 1648-1657. doi: 10.1111/1365-2664.12899

Wigley, T. M., Briffa, K. R., and Jones, P. D. (1984). On the average value of correlated time series, with applications in dendroclimatology and hydrometeorology. J. Clim. Appl. Meteorol. 23, 201-213.

Zang, C. (2012). bootRes: Bootstrapped Response and Correlation Functions. Available online at: https://cran.r-project.org/web/packages/bootRes/index. html (accessed February 26, 2016).

Zarfos, M. R., Dovciak, M., Lawrence, G. B., McDonnell, T. C., and Sullivan, T. J. (2019). Plant richness and composition in hardwood forest understories vary along an acidic deposition and soil-chemical gradient in the northeastern United States. Plant Soil 438, 461-477. doi: 10.1007/s11104-019-04031-y

Conflict of Interest: The authors declare that the research was conducted in the absence of any commercial or financial relationships that could be construed as a potential conflict of interest.

Copyright (c) 2019 Wason, Beier, Battles and Dovciak. This is an open-access article distributed under the terms of the Creative Commons Attribution License (CC BY). The use, distribution or reproduction in other forums is permitted, provided the original author(s) and the copyright owner(s) are credited and that the original publication in this journal is cited, in accordance with accepted academic practice. No use, distribution or reproduction is permitted which does not comply with these terms. 